\title{
Postoperative delirium after cardiac surgery of elderly patients as an independent risk factor for prolonged length of stay in intensive care unit and in hospital
}

\author{
Andrea Kirfel ${ }^{1}$ (D) Jan Menzenbach ${ }^{1}$ (D) $\cdot$ Vera Guttenthaler $^{1} \cdot$ Johanna Feggeler $^{1} \cdot$ Andreas Mayr $^{2}$ (D) $\cdot$ Mark Coburn $^{1}$ (D) \\ Maria Wittmann ${ }^{1}$ (D)
}

Received: 2 November 2020 / Accepted: 19 March 2021 / Published online: 3 April 2021

(c) The Author(s) 2021

\begin{abstract}
Background Postoperative delirium (POD) is a relevant and underdiagnosed complication after cardiac surgery that is associated with increased intensive care unit (ICU) and hospital length of stay (LOS). The aim of this subgroup study was to compare the frequency of tested POD versus the coded International Statistical Classification of Diseases and Related Health Problems (ICD) diagnosis of POD and to evaluate the influence of POD on LOS in ICU and hospital.

Methods 254 elective cardiac surgery patients (mean age, $70.5 \pm 6.4$ years) at the University Hospital Bonn between September 2018 and October 2019 were evaluated. The endpoint tested POD was considered positive, if one of the tests Confusion Assessment Method for ICU (CAM-ICU) or Confusion Assessment Method (CAM), 4 'A's Test (4AT) or Delirium Observation Scale (DOS) was positive on one day.

Results POD occurred in 127 patients (50.0\%). LOS in ICU and hospital were significantly different based on presence (ICU $165.0 \pm 362.7 \mathrm{~h}$; Hospital 26.5 \pm 26.1 days) or absence (ICU 64.5 $\pm 79.4 \mathrm{~h}$; Hospital 14.6 \pm 6.7 days) of POD $(p<0.001)$. The multiple linear regression showed POD as an independent predictor for a prolonged LOS in ICU (48\%; 95\%CI 31-67\%) and in hospital $(64 \%$; 95\%CI $27-110 \%)(p<0.001)$. The frequency of POD in the study participants that was coded with the ICD F05.0 and F05.8 by hospital staff was considerably lower than tests revealed by the study personnel.

Conclusion Approximately 50\% of elderly patients who underwent cardiac surgery developed POD, which is associated with an increased ICU and hospital LOS. Furthermore, POD is highly underdiagnosed in clinical routine.
\end{abstract}

Keywords Postoperative delirium · Cardiac surgery $\cdot$ Elderly patients · Diagnosis of delirium $\cdot$ Length of stay

\section{Introduction}

Postoperative delirium (POD) is an adverse and underdiagnosed postoperative complication of elderly patients [1-3]. Data on the incidence of POD in surgical populations varies in a broad range from 11 to $51 \%$ [2]. Defined by the Diagnostic and Statistical Manual of Mental Disorders, Fifth Edition (DSM-5) and the 10th revision of the International Statistical Classification of Diseases and Related Health Problems (ICD-10), delirium is an acute and fluctuating disturbance of awareness, attention and cognition caused by an organic pathophysiology $[4,5]$. In the literature, POD is divided into different forms, hyperactive, hypoactive and a mixture of both. Especially, the hypoactive delirium often remains undetected in the average clinical setting because of its characteristics such as unawareness, decreased alertness and decreased motor activity [6-10]. 
Numerous risk factors are associated with the development of POD [11]. In addition to predisposing factors of the patient such as age, comorbidities, cognitive and functional impairment, the treatment of the patient like surgical invasiveness and duration of the operation are also causative for POD [2]. In the guideline of the European Society of Anaesthesiology for postoperative delirium, cardiovascular disease is described as a risk factor. It is also reported that comorbidities and a high degree of American Society of Anaesthesiologists (ASA) Physical Status Classification System pose a significant risk for POD [12]. Preoperative anaemia, as another surrogate marker for morbidity, is declared as a risk factor for POD as well as a predictor for a longer stay in hospital and in Intensive care unit (ICU) [12-16]. The combination of advanced age and comorbidities is often found in patients undergoing invasive and major cardiac surgery.

Many studies describe the increased risk of POD associated with cardiac surgery as $9-73 \%$ on average. This variability depends on several factors, such as the characteristics of the patients, the length of stay (LOS) in ICU and the delirium testing modalities. The difference between retrospective data collection using ICD codes and prospective daily testing for delirium by trained personnel is substantial [17-23]. Therefore, the subgroup analysis is focused on the comparison of the frequency of positively tested delirium compared to coded ICD (ICD-10-German Modification) diagnosis delirium in the same patient group.

The occurrence of postoperative delirium affects the workload of nursing staff and has a negative impact on patient outcomes. POD is associated with prolonged ICU and hospital stay, increased mortality and costs $[9,20,22$, 24-31]. To further investigate the influence of POD on LOS, this subgroup analysis includes possible surrogate parameters for morbidity that may influence both POD and LOS. Prolonged LOS in ICU poses a big burden on the limited resources of intensive care beds [32, 33]. Based on these results, the S3 guideline "Analgesia, Sedation and Delirium Management in Critical Care" calls for risk screening and preventive intervention and treatment of POD to reduce the incidence of delirium [34].

Therefore, the aim of this subgroup analysis was to measure the relationship of coded delirium diagnosis in comparison to the actual incidence of tested delirium in patients undergoing cardiac surgery. Furthermore, this study explored the severity of the diseases and analysed the impact of delirium on the length of ICU and hospital stay.

\section{Methods}

\section{Study population}

This prospective monocentre observational trial included 1098 patients from different surgical disciplines of the University Hospital Bonn. From September 2018 to October 2019 , all patients, older than 60 years and with planned operations of at least 60 min duration, were considered eligible for the study. This study was conducted under the title: PRe-Operative Prediction of postoperative DElirium by appropriate SCreening (PROPDESC) and was registered in the German Registry for Clinical Studies under the following number DRKS00015715 [35]. The subgroup analysed here consists of all patients with cardiac surgery included in PROPDESC. The enrolled cohort of 308 patients consisted mainly of coronary artery bypass surgery (CABG), valve replacement or repair, or combined $C A B G$ with valve replacement or repair. Exclusion criteria included emergency procedures, language barriers or missing compliance with the study protocol. The present study complied within the principles of the declaration of Helsinki and was approved by the local institutional Ethics Committee at the Medical Faculty of the Rheinische Friedrich-Wilhelms-University of Bonn. Written informed consent was obtained from each patient.

\section{Data collection}

For each enrolled patient, 50 variables were collected. In this subgroup analyses, preoperative risk stratification such as ASA Physical Status Classification System, age, sex, number of medications, haemoglobin and the type of surgery were applied. Postoperative clinical variables were recorded including length of the intensive care unit stay (ICU-LOS) and LOS in the hospital. After discharge from the hospital, billing-relevant data such as the number of ICD codes and the severity of inpatient treatment were evaluated for each patient in the form of the German Patient Clinical Complexity Level (PCCL). In the German Diagnosis Related Group (G-DRG) classification, complications and/or comorbidities $(\mathrm{CC})$ are mapped using the patient-related total severity code (PCCL). The PCCL is calculated from the cumulative severities of complications and/or comorbidities (CCL) of a patient's individual.

The data for the external comparison with regard to ICD-10-GM coding and the information on PCCL and LOS was taken from the Institut für das Entgeltsystem im Krankenhaus gGmbH (InEK) browser database 2019 [36]. The classification for postoperative delirium is listed in the ICD-10-GM Catalogue under Chapter V with the class title "Mental and Behavioural Disorders" under category 
F05.- with the designation "delirious, not caused by alcohol or other psychotropic substances". The number of positive delirium results assessed by study personnel were compared to those coded by the hospital staff (ICD codes F05.0 and F05.8). To classify the individual cardiac surgery procedures, the German Operation and Procedure Code (OPS) classification 2019 was used.

\section{Delirium assessment}

Delirium assessments were conducted every morning by trained doctoral students on each of the first 5 days after surgery, respectively, on the first 5 days' post-sedation. For this purpose, several standardized tests were used. To avoid missing delirium diagnosis in the context of spot examinations, the Delirium Observation Scale (DOS) was additionally applied by interviewing the nursing staff to assess the previous $24 \mathrm{~h}$. Regarding the 5-day visit period, we used different test procedures for the intensive care and normal ward. Confusion Assessment Method for ICU (CAM-ICU) was used for intensive care patients. The Confusion Assessment Method (CAM) and the 4 'A's Test (4AT) were conducted in patients on the normal ward. The endpoint of a positive delirium diagnosis was considered to be fulfilled if one of the applied assessment methods detected POD on at least one of the 5 days. The aim of the overall PROPDESC study was to establish a sensitive risk score for postoperative delirium, thus different testing procedures were used in parallel to avoid missing any delirium abnormalities in the study cohort. Based on this subgroup analysis, the primary endpoint was maintained based on a positive test result from the various assessment tools. In accordance with good clinical practice, doctoral students were trained and monitored in the performance of each test at the beginning of the study. Regular quality assurance meetings were held throughout the study [35].

\section{Data analysis}

Statistical analysis was performed using the statistical programming environment $\mathrm{R}$. Continuous and ordinal variables are presented with mean and \pm standard deviation (sd). Nominal variables are displayed as numbers and percentages. Furthermore, the comparison between the delirium tested by trained study personnel and the coded delirium at the University Hospital Bonn and the average in Germany is presented by means of percentages. The grouping of individual procedures was performed on the basis of the billed diagnosis related groups (DRG). The same procedure was used to assess the LOS and the severity of treatment with PCCL.

Differences between the two groups (POD versus no POD) regarding preoperative factors were analysed using the non-parametric Mann-Whitney test for continuous variables. For categorical variables, Fisher's exact test was computed to check for independence.

To assess the independent effect of POD on LOS in ICU or in hospital, multi-variable linear regression analysis was performed to adjust for potential preoperative confounders. The LOS outcomes were log-transformed to ensure approximate normality of residuals. POD was entered as binary explanatory variable, while adjusting for preoperative surrogate parameters for morbidity (age, number of medication, ASA, preoperative haemoglobin value). To ensure interpretability, the coefficients of POD were re-transformed and are presented in percent increase (compared to non-POD) with corresponding $95 \%$ confidence intervals reflecting adjusted relative effects of POD on LOS.

\section{Results}

The subgroup included 308 patients, 14 (4.5\%) patients were not operated, 15 (4.9\%) patients died and 4 (1.3\%) patients were still sedated when transferred to a further facility. 18 (5.8\%) of the included patients received pacemaker or minimal invasive surgery and were removed from the analysed patient group based on the lack of complexity of the procedure. Three (1.0\%) patients have withdrawn their consent and are, therefore, considered to be study dropout (Fig. 1). Thus, 254 patients with a mean age of $70.5( \pm 6.4)$ years were included in the analyses. The gender distribution was $72(28.4 \%)$ women and $182(71.7 \%)$ men. We divided these patients into two groups based on the presence or absence of tested delirium: the POD group $(n=127,50.0 \%)$ and the non-POD group $(n=127,50.0 \%)$. For the evaluation on the basis of the billed DRG, one case is not included, since this case was billed with the previously performed pacemaker operation despite the heart valve operation.

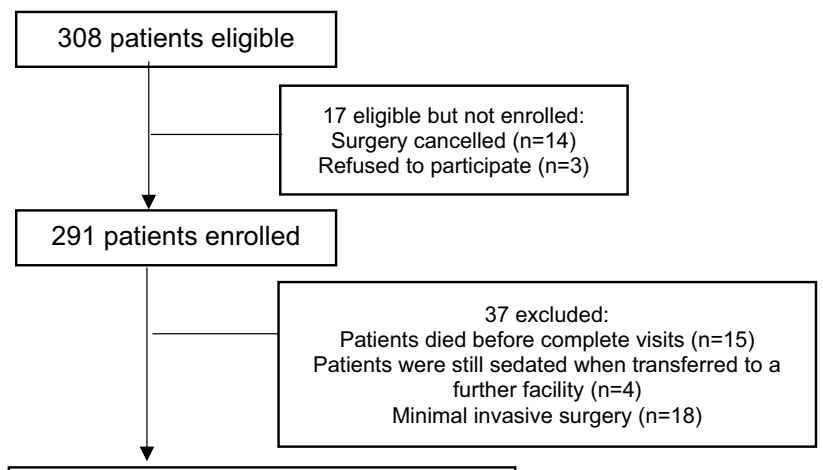

254 patients included in the analyses

Fig. 1 Flowchart of subgroup patient selection 


\section{Procedural coding of POD}

The ICD code F05.0 "Delirium without dementia" was coded $38(15.0 \%)$ times in the included patient group of the University Hospital Bonn and the diagnosis F05.8 "Other form of delirium" was coded 15 (5.9\%) times. Among the F05.0 positively coded patients, 33 (86.8\%) were tested positive by the study personnel in the specified assessment window and 14 (93.3\%) of the F05.8 coded patients have also been tested positive. The percentage of positive POD patients in PROPDESC is consistently higher than the coded diagnoses in the University Hospital Bonn and the German average (Table 1). The tested delirium incidence ranges from an average of $35.5 \%$ up to $100 \%$. In our trial, we found a rate of positive tested delirium for patients with heart valve surgeries of $58.5 \%$, whereas the InEK data of coded ICD diagnoses for delirium was in total $14.3 \%$ in this group of patients. For CABG patients in our trial the incidence of delirium was $35.6 \%$, whereas the InEK shows an average percentage of $18.7 \%$. In addition, we found that the percentage frequency of coded delirium diagnoses at the University
Table 1 Distribution of ICD codes and positive POD test results

\begin{tabular}{|c|c|c|c|c|c|}
\hline & & \multirow[t]{2}{*}{ Total } & \multicolumn{2}{|c|}{ POD group } & \multirow{2}{*}{$\begin{array}{l}\text { POD group } \\
\text { PROPDESC }\end{array}$} \\
\hline & & & F05.0 & F05.8 & \\
\hline & & $\mathrm{n}$ & $\%(\mathrm{n})$ & $\%(\mathrm{n})$ & $\%(\mathrm{n})$ \\
\hline \multicolumn{6}{|l|}{ Heart valve surgery } \\
\hline & University hospital & 94 & $14.9(14)$ & $3.2(3)$ & $58.5(55)$ \\
\hline & InEK database & 5,929 & 2.8 & 11.5 & \\
\hline \multicolumn{6}{|l|}{ CABG } \\
\hline & University hospital & 87 & $8.1(7)$ & $3.5(3)$ & $35.6(31)$ \\
\hline & InEK database & 6,870 & 3.8 & 14.9 & \\
\hline \multicolumn{6}{|l|}{ Complex intervention } \\
\hline & University hospital & 7 & 0.0 & $14.3(1)$ & $71.4(5)$ \\
\hline & InEK database & 1,575 & 1.2 & 8.9 & \\
\hline \multicolumn{6}{|c|}{ ICU complex treatment } \\
\hline & University hospital & 10 & $60.0(6)$ & $20.0(2)$ & $90.0(9)$ \\
\hline & InEK database & 1,730 & 9.3 & 23.2 & \\
\hline \multicolumn{6}{|l|}{ Ventilation $>24 \mathrm{~h}$} \\
\hline & University hospital & 31 & $12.9(4)$ & $6.5(2)$ & $35.5(11)$ \\
\hline & InEK database & 1,366 & 5.6 & 13.0 & \\
\hline \multicolumn{6}{|l|}{ Ventilation $>95 \mathrm{~h}$} \\
\hline & University hospital & 13 & $23.1(3)$ & 0.0 & $38.5(5)$ \\
\hline & InEK database & 4,075 & 7.3 & 16.0 & \\
\hline \multicolumn{6}{|l|}{ Ventilation $>249 \mathrm{~h}$} \\
\hline & University hospital & 4 & $50.0(2)$ & 0.0 & $75.0(3)$ \\
\hline & InEK database & 2,731 & 8.8 & 14.6 & \\
\hline \multicolumn{6}{|l|}{ Ventilation $>499 \mathrm{~h}$} \\
\hline & University hospital & 3 & $33.3(1)$ & $33.3(1)$ & $100.0(3)$ \\
\hline & InEK database & 180 & 13.9 & 15.0 & \\
\hline \multicolumn{6}{|l|}{ Ventilation $>1799 \mathrm{~h}$} \\
\hline & University hospital & 4 & $25.0(1)$ & $50.0(2)$ & $100.0(4)$ \\
\hline & InEK database & 83 & 18.8 & 22.1 & \\
\hline
\end{tabular}

This table shows the relative frequency of coded delirium diagnoses (ICD F05.0 and F05.8) at the Bonn University Hospital and in the InEK database, as well as the relative frequency of positively tested delirium patients. For ease of comparison, the individual billing codes (DRGs) are grouped under the terms of the main interventions. The following DRGs are summarized under the respective main interventions: Heart valve surgery included DRGs: F03A-F03C, F03E-F03F; CABG included DRGs: F05Z, F06A-F06E; Complex intervention included DRGs: F07B-F07C; ICU complex treatment included DRGs: F36A-F36C; Ventilation > $24 \mathrm{~h}$ included DRG: F43B; Ventilation duration > $95 \mathrm{~h}$ included DRGs: A13A, A13D-A13E; Ventilation duration > 249 h included DRGs: A11A-A11B, A11E; Ventilation duration > 499 h included DRG: A09A; Ventilation > $1799 \mathrm{~h}$ included DRGs: A06A-A06B

POD postoperative delirium, CABG coronary artery bypass grafting, ICU intensive care unit, InEK Institut für das Entgeltsystem im Krankenhaus gGmbH 
Hospital Bonn (CABG 11.5\%; heart valve surgery 18.1\%) was considerably lower than that of the same patients who were tested positive by study personnel (CABG 35.6\%; heart valve surgery $58.5 \%$ ). In addition to the ICU complex treatments, the combination procedures involving CABG and heart valve surgery (71.4\%) showed the highest tested delirium incidence.

\section{Comparison of comorbidity}

The average severity of disease, expressed in PCCL, was not predominantly higher in university hospital patients than in the patients in the InEK comparison (Table 2). This is explained by the fact that most cardiac surgeries are performed at university hospitals and therefore the severity of the InEK patients is similar to the severity of the patients examined here. Within the entire subgroup, 188 (74.3\%) patients were billed on the basis of cardiac surgery and 65 (25.7\%) on the basis of the more complex intensive care treatment after the cardiac surgery. The presence of delirium showed statistically significant differences in the preoperatively determined haemoglobin value (no delirium: $14.0 \pm 1.6 \mathrm{~g} / \mathrm{dl}$; delirium: $13.4 \pm 1.8 \mathrm{~g} / \mathrm{dl} ; p<0.009)$, the number of ICD codes (no delirium: $13.5 \pm 5.3$; delirium

Table 2 List of severity levels by Patient Clinical Complexity Level (PCCL) and average length of stay (LOS)

\begin{tabular}{|c|c|c|c|c|c|c|c|c|c|c|}
\hline & & Total & $\begin{array}{l}\text { LOS in hospital } \\
\text { (days) }\end{array}$ & $\begin{array}{l}\text { PCCL } \\
0\end{array}$ & $\begin{array}{l}\text { PCCL } \\
1\end{array}$ & $\begin{array}{l}\text { PCCL } \\
2\end{array}$ & $\begin{array}{l}\text { PCCL } \\
3\end{array}$ & $\begin{array}{l}\text { PCCL } \\
4\end{array}$ & $\begin{array}{l}\text { PCCL } \\
5\end{array}$ & $\begin{array}{l}\text { PCCL } \\
6\end{array}$ \\
\hline & & $\mathrm{N}$ & mean & $\%(\mathrm{n})$ & $\%(\mathrm{n})$ & $\%(\mathrm{n})$ & $\%(\mathrm{n})$ & $\%(\mathrm{n})$ & $\%(\mathrm{n})$ & $\%(\mathrm{n})$ \\
\hline \multicolumn{11}{|l|}{ Heart valve surgery } \\
\hline & University hospital & 94 & 18.6 & $20.2(19)$ & $1.1(1)$ & $7.5(7)$ & $35.1(33)$ & $26.6(25)$ & $9.6(9)$ & $0.0(0)$ \\
\hline & InEK database & 5,929 & 14.5 & 19.2 & 6.5 & 14.2 & 28.4 & 23.8 & 7.8 & 0.2 \\
\hline \multicolumn{11}{|l|}{ CABG } \\
\hline & University hospital & 87 & 15.1 & $10.3(9)$ & $10.3(9)$ & $21.8(19)$ & $31.0(27)$ & $18.4(16)$ & $8.1(7)$ & $0.0(0)$ \\
\hline & InEK database & 6,870 & 19.0 & 8.2 & 6.6 & 11.7 & 21.2 & 34.8 & 16.3 & 1.3 \\
\hline \multicolumn{11}{|l|}{ Complex intervention } \\
\hline & University hospital & 7 & 13.6 & $14.3(1)$ & $0.0(0)$ & $0.0(0)$ & $28.6(2)$ & $42.9(3)$ & $14.3(1)$ & $0.0(0)$ \\
\hline & InEK database & 1,575 & 13.5 & 14.7 & 3.9 & 9.4 & 28.3 & 28.4 & 14.4 & 1.0 \\
\hline \multicolumn{11}{|c|}{ ICU complex treatment } \\
\hline & University hospital & 10 & 30.8 & $0.0(0)$ & $0.0(0)$ & $0.0(0)$ & $0.0(0)$ & $40.0(4)$ & $50.0(5)$ & $10.0(1)$ \\
\hline & InEK database & 1,730 & 29.6 & 0.5 & 1.0 & 1.9 & 13.8 & 33.1 & 41.8 & 8.0 \\
\hline \multicolumn{11}{|l|}{ Ventilation $>24 \mathrm{~h}$} \\
\hline & University hospital & 31 & 15.8 & $0.0(0)$ & $3.2(1)$ & $16.1(5)$ & $54.8(17)$ & $25.8(8)$ & $0.0(0)$ & $0.0(0)$ \\
\hline & InEK database & 1,366 & 17.6 & 2.3 & 3.3 & 10.4 & 35.5 & 45.6 & 2.9 & 0.0 \\
\hline \multicolumn{11}{|l|}{ Ventilation $>95 \mathrm{~h}$} \\
\hline & University hospital & 13 & 23.5 & $0.0(0)$ & $7.7(1)$ & $7.7(1)$ & $53.9(7)$ & $23.1(3)$ & $7.7(1)$ & $0.0(0)$ \\
\hline & InEK database & 4,075 & 23.1 & 3.7 & 3.1 & 6.3 & 28.4 & 42.0 & 16.2 & 0.2 \\
\hline \multicolumn{11}{|l|}{ Ventilation $>249 \mathrm{~h}$} \\
\hline & University hospital & 4 & 32.3 & $0.0(0)$ & $0.0(0)$ & $25.0(1)$ & $0.0(0)$ & $50.0(2)$ & $25.0(1)$ & $0.0(0)$ \\
\hline & InEK database & 2,731 & 34.3 & 2.7 & 2.7 & 7.1 & 27.8 & 37.8 & 20.5 & 1.4 \\
\hline \multicolumn{11}{|l|}{ Ventilation $>499 \mathrm{~h}$} \\
\hline & University hospital & 3 & 93.7 & $0.0(0)$ & $0.0(0)$ & $0.0(0)$ & $0.0(0)$ & $0.0(0)$ & $66.7(2)$ & $33.3(1)$ \\
\hline & InEK database & 180 & 58.5 & 0.0 & 0.0 & 0.6 & 2.2 & 25.0 & 61.1 & 11.1 \\
\hline \multicolumn{11}{|l|}{ Ventilation $>1799 \mathrm{~h}$} \\
\hline & University hospital & 4 & 132.8 & $0.0(0)$ & $0.0(0)$ & $0.0(0)$ & $0.0(0)$ & $0.0(0)$ & $25.0(1)$ & $75.0(3)$ \\
\hline & InEK database & 83 & 111.9 & 0.0 & 0.0 & 0.0 & 3.5 & 7.6 & 39.5 & 49.3 \\
\hline
\end{tabular}

This table shows the comparison of the Patient Clinical Complexity Level (PCCL) of the tested patients of the University Hospital Bonn and the data of the InEK. For ease of comparison, the individual billing codes (DRGs) are grouped under the terms of the main interventions. The following DRGs are summarized under the respective main interventions: Heart valve surgery included DRGs: F03A-F03C, F03E-F03F; CABG included DRGs: F05Z, F06A-F06E; Complex intervention included DRGs: F07B-F07C; ICU complex treatment included DRGs: F36A-F36C; Ventilation > $24 \mathrm{~h}$ included DRG: F43B; Ventilation duration > $95 \mathrm{~h}$ included DRGs: A13A, A13D-A13E; Ventilation duration > $249 \mathrm{~h}$ included DRGs: A11A-A11B, A11E; Ventilation duration > 499 h included DRG: A09A; Ventilation > 1799 h included DRGs: A06A-A06B

PCCL German Patient Clinical Complexity Level, LOS length of stay, InEK Institut für das Entgeltsystem im Krankenhaus gGmbH, CABG coronary artery bypass grafting, ICU intensive care unit 
$18.5 \pm 10.3 ; p<0.001$ ) and the level of PCCL (no delirium: $2.6 \pm 1.4$; delirium $3.4 \pm 1.5 ; p<0.001$ ) after discharge from hospital (Table 3). The ASA classification, number of different medication taken before surgery and age of the patients did not differ significantly between the delirious and nondelirious patients. The mean age was $70.9( \pm 6.4)$ years for the delirious patients and $70( \pm 6.3)$ years for the non-delirious patients. Based on their underlying cardiac disease, $77 \%$ $(n=195)$ of patients were grouped with ASA 3 (Table 3$)$.

\section{Relationship between delirium and LOS}

Table 2 compares the average LOS of patients of the PROPDESC study patients at the University Hospital Bonn with the average LOS of patients in the InEK database. Patients at the University Hospital had different LOS (valve surgery 18.6 days; CABG 15.1 days) compared to the mean value of the InEK population (valve surgery 14.5 days; CABG 19.0 days). Patients manifesting delirium had a significantly longer LOS in hospital (no delirium: 14.6 \pm 6.7 days; delirium $26.5 \pm 26.1$ days; $p<0.001$ ) (Table 3). Furthermore, the study results display that patients with a POD are hospitalized on average 12 days longer (Table 3). The study results confirm that the LOS in hospital is nearly twice as long in patients with POD after cardiac surgery $(26.5 \pm 26.1$ days $)$ compared to the average LOS of this patient group (14.6 \pm 6.7 days). The results of the linear regression model support this statement (Table 4). They showed that patients with POD have a $48 \%$ (95\% CI 31-67\%) increase in LOS in hospital even when adjusting for potential confounders.

In addition to this, the study results demonstrate that patients with delirium had a significantly longer ICU LOS (no delirium: $64.5 \pm 79.4 \mathrm{~h}$; delirium $165.0 \pm 362.7 \mathrm{~h}$; $p<0.001$ ) (Table 3). In total, the delirious study patients had a 2.5 times longer intensive care stay than the group of

Table 4 POD as an independent predictor for LOS in the ICU and in hospital: effects were adjusted for preoperative risk factors via a multi-variable linear regression model and are presented as increase in percent

\begin{tabular}{llll}
\hline & POD (adj. effect) & $95 \%$ CI & $p$ value \\
\hline LOS in ICU (hours) & $+48 \%$ & $+31 \%$ to $+67 \%$ & $<0.001$ \\
$\begin{array}{lll}\text { LOS in hospital } \\
\text { (days) }\end{array}$ & $+64 \%$ & $+27 \%$ to $+110 \%$ & $<0.001$ \\
\hline
\end{tabular}

POD postoperative delirium, CI Confidence Interval, ICU intensive care unit, LOS length of stay

POD effect adjusted for preoperative surrogate parameters for morbidity (age, number of medication, ASA, preoperative haemoglobin value)
Table 3 Perioperative risk factors for POD

\begin{tabular}{llllr}
\hline & Total & POD group & Non-POD group & $p$ value \\
\hline No. (\%) & 254 & $127(50.0)$ & $127(50.0)$ & - \\
Age (years) & $70.5 \pm 6.4$ & $70.9 \pm 6.4$ & $70.0 \pm 6.3$ & 0.229 \\
No. of coded ICD & $16.0 \pm 8.6$ & $18.5 \pm 10.3$ & $13.5 \pm 5.3$ & $<0.001$ \\
No. of medication & $6.1 \pm 2.9$ & $6.3 \pm 3.0$ & $5.9 \pm 2.8$ & 0.196 \\
Haemoglobin (g/dl) & $13.7 \pm 1.7$ & $13.4 \pm 1.8$ & $14.0 \pm 1.6$ & 0.009 \\
Level of PCCL & $3.0 \pm 1.5$ & $3.4 \pm 1.5$ & $2.6 \pm 1.4$ & $<0.001$ \\
PCCL level 0 & & $7.0(9)$ & $15.9(20)$ & \\
PCCL level 1 & & $3.9(5)$ & $5.6(7)$ & \\
PCCL level 2 & & $11.7(15)$ & $14.3(18)$ & \\
PCCL level 3 & & $26.8(34)$ & $40.9(52)$ & \\
PCCL level 4 & & $28.9(37)$ & $19.8(25)$ & 0.638 \\
PCCL level 5 & & $17.2(22)$ & $4.0(5)$ & \\
PCCL level 6 & & $3.9(5)$ & $0.0(0)$ & $<0.001$ \\
Level of ASA & & $3.2 \pm 0.5$ & $3.2 \pm 0.5$ & \\
ASA level 1 & $3.2 \pm 0.5$ & $0.8(1)$ & $0.0(0)$ & \\
ASA level 2 & & $1.6(2)$ & $4.0(5)$ & $76.4(97)$ \\
ASA level 3 & & $77.2(98)$ & $19.8(25)$ & $14.6 \pm 6.7$ \\
ASA level 4 & & $20.3(26)$ & $64.5 \pm 79.4$ & \\
LOS in hospital (days) & $20.6 \pm 20.0$ & $26.5 \pm 26.1$ & $165.0 \pm 362.7$ & \\
LOS ICU (hours) & $114.8 \pm 266.8$ & & &
\end{tabular}

POD postoperative delirium, PCCL German Patient Clinical Complexity Level, ASA American Society of Anaesthesiologists, LOS length of stay, ICU intensive care unit

Data are expressed as mean \pm standard deviation. The frequencies of the individual levels of PCCL and ASA are shown in percent and $(=n)$ 
patients without delirium. The average time difference was $100 \mathrm{~h}$ and was caused by the fact that study patients with delirium stayed 4.2 days longer in ICU. The results of the linear regression confirm delirium as an independent predictor of LOS in ICU (Table 4). Following our model, patients with POD have a 64\% (95\% CI: 27-110\%) increase in LOS in ICU independently from their preoperative risk factors.

\section{Discussion}

POD is a common complication of elderly patients after cardiac surgery and has a high impact on LOS in ICU and hospital. Furthermore, the secondary diagnosis of POD is clearly underdiagnosed, demonstrating the extent to which this secondary diagnosis is underestimated. The incidence in the present study was $50.0 \%$ and thus in between the $9 \%$ and $73 \%$ stated in the literature [17-23]. Explanations for this variability in the literature could be a different extent and different instruments of studies to assess POD [11]. While PROPDESC used several tools (two for ICU and three on normal ward) other studies evaluated POD with one tool or used the retrospective analysis of ICD codes. In this study, we compared the number of positive tested delirious patients (from 35.5 to $100 \%$ ) with the coded delirious diagnosis (ICD F05.0 and F05.8) in the University Hospital Bonn and the German-wide average (from 10.3 to $40.9 \%$ ). We found that the percentage frequency of reported delirium diagnoses in the considered group of patients was significantly lower than as tested positive by study personnel. The difference was $40.4 \%$ for heart valve surgery and $24.1 \%$ for CABG. There are several explanations for this significant difference. Prior work has described a range up to $80 \%$ of the hypoactive subtype of delirium $[6,10,20,23,37,38]$. These results suggest that the form of hypoactive POD often remains undetected by hospital staff and is, therefore, not so present in the reported ICDs. Furthermore, this could also lead to the assumption that there is no standardized delirium testing, as pointed-out by various studies and guidelines [12, 39-45]. It should also be noted that in the German DRG system, the share of material costs for heart valve surgery and CABG, accounts for more than a quarter of total costs (heart valve surgery F03A-F03F 30-37\% material costs; CABG F05Z, F06A-F06E 23-30\% material costs) [36]. Considering the high material costs, the coding of delirium does not result in a relevant surcharge and might be, therefore, neglected as a complication and comorbidity. This leads to the conclusion that from a medico-economic perspective there is no incentive to diagnose POD. However, various examples can be found in the existing literature that the nursing effort in combination with a POD increases significantly and thus, the cost-relevant effort as well $[9,20,46]$.
Prior work has documented that a high number of comorbidities, severe diseases and advanced age occur more frequently among the delirious patients [12]. Our data confirm the results of previous studies that comorbidities have an influence on the development of POD which is shown by the significantly higher number of ICD codes and PCCL of delirious patients [2, 12, 20,38]. However, we could not find a significant difference between the POD and the non-POD groups in terms of age, number of preoperative medication and ASA classification preoperatively. So far, only few studies have dealt with the hypothesis whether patients have a more complex and longer course of inpatient treatment due to delirium, or whether the present morbidity is the main reason for this. One study confirmed that the prolonged intensive care stay of cardiac surgery patients is based on the complication of POD and not on the pre-existing morbidity [20]. However, POD is very often recognized as an effect on ICU LOS and length of hospital stay [20,47-51]. In this study, we were able to show that POD is independently associated with an increased LOS in ICU and in hospital among patients undergoing cardiac surgery and, also an extended length of hospital stay compared to the German average. Based on the PCCL comparison between the PROPDESC patients and the German average, the argument that the study population is sicker and, therefore, has a longer stay is not supported by the results of our analysis. On the contrary, we were able to confirm via multiple linear regression that POD has an independent effect on LOS after adjusting for preoperative surrogate parameters for morbidity.

Although the results of this subgroup study analysis demonstrate causality only for surrogate parameters, they underline the importance of detection of POD in elderly cardiac surgery patients. Delirium poses additional work on the nursing staff and prolongs the duration of the ICU stay by an average of 4.2 days. If German hospitals would introduce standardized preoperative risk screening and prevention programmes to increase the awareness of a possible POD, the incidence of delirious patients might be reduced [52-56]. If standardized screening with containment prevention and therapy of POD could reduce the LOS in ICU, this would have a considerable impact on the limited capacities of German intensive care units. Among the 254 patients included in this study over the period of 1 year, approximately 50\% were delirious after their surgery. A reduction of the LOS of this patient group by one day (from an average of 7 to 6 days) would result in the free capacity of an intensive care bed for 127 days per year. According to the University Hospital Bonn's quality report, $720 \mathrm{CABG}$ and heart valve surgeries were performed in 2018. If an extrapolated 50\% of the patients in the total population had shown delirium, this would have resulted in 360 patients. By reducing the LOS on ICU by only 1 day, the capacity of one bed in a 
12-bed ICU would be available for about 1 year (360 days) for additional patients.

Based on the results of this study POD has an impact on LOS in ICU and is rarely diagnosed in clinical routine. If the delirium diagnosis does not have a relevant influence on the billing amount, the reduction of the incidence of delirium should be focussed on medical-economic aspects to improve the capacity utilization of the bottleneck in ICUs.

\section{Study limitation}

This study has several limitations. One limitation is the small sample size, related to the character of the subgroup analyses. In connection with the regression analysis, there might be unknown confounding factors for which we were not able to adjust for. These factors could additionally influence both POD and the LOS. Furthermore, the delirious PROPDESC patients were only based on the result of a positive test result of the study staff and has no delirium diagnosis by a psychologist. The comparison with the nationwide ICD diagnoses of POD and other data from the InEK browser database is based on data from 2019, but the patients of this subgroup were enrolled during 2018 and 2019. Based on the coding guidelines, only ICDs with associated inpatient treatment costs are coded and, therefore, do not represent the total comorbidities of patients. In addition, the summarized Tables with the DRG overview do not clearly show which interventions the intensive complex treatments are based on.

\section{Conclusion}

Postoperative delirium is associated with a significantly increased LOS in hospital as well as ICU. The frequency of ICD coding of POD in the subgroup analysis as well as in the internationally available accounting data is considerably lower than the tested incidence of POD. Based on the underlying billing system, there is no financial incentive for ICD coding of POD in cardiac surgery patients, so this could be a possible reason for the low coding rate of this secondary diagnosis. Future research should evaluate the introduction of standardized, fast and simple preoperative risk screening followed by prevention programmes to reduce the incidence of delirium and its impact on LOS.

Authors' contributions VG, JM and MW contributed to the development of the original protocol; MC critically reviewed the trial protocol; JM is the PI of the study; AK and JF contributed to patient recruitment; MW and AK are responsible for the design of this sub-study; AK performed the descriptive and bivariate analyses and wrote the first draft; AM performed the regression analyses; all authors critically reviewed the manuscript for important intellectual content and approved the final version submitted for publication.

Funding Open Access funding enabled and organized by Projekt DEAL.. The PROPDESC trial is supported by the funding instrument for clinical trials (Förderungsinstrument der Kommission für Klinische Studien (FKS)) of the Trial-Centre Bonn (Studienzentrum Bonn (SZB)) at the University Hospital Bonn (UKB) (Application: 2018-FKS-01/ Grant: O-417.0002). The funder did not have any impact in the design of the study and collection, analysis and interpretation of the data and in writing the manuscript.

Availability of data and materials The data sets generated and/or analysed during the study are available on request from the corresponding author.

Code availability The $\mathrm{R}$ code used for the analysis is available on request from the corresponding author.

\section{Declarations}

Conflicts of interest The authors declare no conflict of interest.

Ethics approval This study was performed in line with the principles of the Declaration of Helsinki. Approval was granted by the Ethics Committee of University Bonn (Ethics Committee at the Medical Faculty of the Rheinische Friedrich-Wilhelms-University of Bonn) (Date 18.09.2017/No. 255/17 Ethical Approval Document 1). The study protocol including amendments was finalized on $2^{\text {nd }}$ of May 2018 as version 2.1 (Ethical Approval Document 2).

Informed consent Each patient has given written informed consent to participate in the study.

Open Access This article is licensed under a Creative Commons Attribution 4.0 International License, which permits use, sharing, adaptation, distribution and reproduction in any medium or format, as long as you give appropriate credit to the original author(s) and the source, provide a link to the Creative Commons licence, and indicate if changes were made. The images or other third party material in this article are included in the article's Creative Commons licence, unless indicated otherwise in a credit line to the material. If material is not included in the article's Creative Commons licence and your intended use is not permitted by statutory regulation or exceeds the permitted use, you will need to obtain permission directly from the copyright holder. To view a copy of this licence, visit http://creativecommons.org/licenses/by/4.0/.

\section{References}

1. Ryan DJ, O'Regan NA, Caoimh RÓ et al (2013) Delirium in an adult acute hospital population: predictors, prevalence and detection. BMJ Open 3:e001772. https://doi.org/10.1136/bmjop en-2012-001772

2. Inouye SK, Westendorp RG, Saczynski JS (2014) Delirium in elderly people. The Lancet 383:911-922. https://doi.org/10.1016/ S0140-6736(13)60688-1

3. Rieck KM, Pagali S, Miller DM (2020) Delirium in hospitalized older adults. Hosp Pract 48:3-16. https://doi.org/10.1080/21548 331.2019.1709359 
4. American Psychiatric Association (2013) Diagnostic and statistical manual of mental disorders. Fifth Edition, American Psychiatric Association

5. World Health Organization. (2015) International Statistical Classification of Disease and Related Health Problems 10th Revision

6. Stransky M, Schmidt C, Ganslmeier P et al (2011) Hypoactive Delirium After Cardiac Surgery as an Independent Risk Factor for Prolonged Mechanical Ventilation. J Cardiothorac Vasc Anesth 25:968-974. https://doi.org/10.1053/j.jvca.2011.05.004

7. Meagher DJ, Leonard M, Donnelly S et al (2012) A longitudinal study of motor subtypes in delirium: frequency and stability during episodes. J Psychosom Res 72:236-241. https://doi.org/10. 1016/j.jpsychores.2011.11.013

8. Yang FM, Marcantonio ER, Inouye SK et al (2009) Phenomenological subtypes of delirium in older persons: patterns, prevalence, and prognosis. Psychosomatics 50:248-254. https://doi.org/10. 1176/appi.psy.50.3.248

9. Weinrebe W, Johannsdottir E, Karaman M, Füsgen I (2016) What does delirium cost? An economic evaluation of hyperactive delirium. Z Für Gerontol Geriatr 49:52-58. https://doi.org/10.1007/ s00391-015-0871-6

10. Zhang W, Hu W, Shen $\mathrm{M}$ et al (2016) Profiles of delirium and the clinical outcomes of patients who underwent coronary artery bypass grafting: a prospective study from China. J Clin Nurs 25:631-641. https://doi.org/10.1111/jocn.13089

11. Lindroth H, Bratzke L, Purvis S et al (2018) Systematic review of prediction models for delirium in the older adult inpatient. BMJ Open 8:e019223. https://doi.org/10.1136/bmjopen-2017-019223

12. Aldecoa C, Bettelli G, Bilotta F et al (2017) European Society of Anaesthesiology evidence-based and consensus-based guideline on postoperative delirium. Eur J Anaesthesiol 34:192-214. https:// doi.org/10.1097/EJA.0000000000000594

13. Deutsche Gesellschaft für Anästhesiologie und Intensivmedizin (DGAI) inKooperation mit der Arbeitsgemeinschaft der WissenschaftlichenMedizinischen Fachgesellschaften (AWMF) (2018) Präoperative Anämie, Diagnostik und Therapie der Anämie, Leitlinie, AWMF Registernummer 001 - 0024, Version 1.0

14. Kazmierski J, Kowman M, Banach M et al (2010) Incidence and predictors of delirium after cardiac surgery: results from The IPDACS Study. J Psychosom Res 69:179-185. https://doi.org/ 10.1016/j.jpsychores.2010.02.009

15. Dakour-Aridi H, Ou MT, Locham S et al (2020) Anemia as an independent predictor of adverse outcomes after carotid revascularization. J Vasc Surg. https://doi.org/10.1016/j.jvs.2020.01.065

16. Hung M, Besser M, Sharples LD et al (2011) The prevalence and association with transfusion, intensive care unit stay and mortality of pre-operative anaemia in a cohort of cardiac surgery patients. Anaesthesia 66:812-818. https://doi.org/10.1111/j.1365-2044. 2011.06819.x

17. Simeone S, Pucciarelli G, Perrone M et al (2018) Delirium in ICU patients following cardiac surgery: an observational study. J Clin Nurs 27:1994-2002. https://doi.org/10.1111/jocn.14324

18. Habeeb-Allah A, Alshraideh JA (2019) Delirium post-cardiac surgery: incidence and associated factors. Nurs Crit Care Nicc. https://doi.org/10.1111/nicc.12492

19. Veliz-Reissmüller G, Torres HA, van der Linden J et al (2007) Pre-operative mild cognitive dysfunction predicts risk for postoperative delirium after elective cardiac surgery. Aging Clin Exp Res 19:172-177. https://doi.org/10.1007/BF03324686

20. Brown CH, Laflam A, Max L et al (2016) The impact of delirium after cardiac surgical procedures on postoperative resource use. Ann Thorac Surg 101:1663-1669. https://doi.org/10.1016/j.athor acsur.2015.12.074

21. Ogawa M, Izawa KP, Satomi-Kobayashi S et al (2018) Preoperative exercise capacity is associated with the prevalence of postoperative delirium in elective cardiac surgery. Aging Clin Exp Res 30:27-34. https://doi.org/10.1007/s40520-017-0736-5

22. Kotfis K, Szylińska A, Listewnik M et al (2018) Early delirium after cardiac surgery: an analysis of incidence and risk factors in elderly ( $\geq 65$ years) and very elderly ( $\geq 80$ years) patients. Clin Interv Aging 13:1061-1070. https://doi.org/10.2147/CIA.S1669 09

23. Sanson G, Khlopenyuk Y, Milocco S et al (2018) Delirium after cardiac surgery. Incidence, phenotypes, predisposing and precipitating risk factors, and effects. Heart Lung 47:408-417. https:// doi.org/10.1016/j.hrtlng.2018.04.005

24. Park K (2019) Postoperative delirium is associated with negative outcomes and long-term mortality in elderly koreans: a retrospective observational study. Medicina (Mex) 55:618. https://doi.org/ 10.3390/medicina55100618

25. Janssen TL, Steyerberg EW, Langenberg JCM et al (2019) Multimodal prehabilitation to reduce the incidence of delirium and other adverse events in elderly patients undergoing elective major abdominal surgery: an uncontrolled before-and-after study. PLoS ONE 14:e0218152. https://doi.org/10.1371/journal.pone.0218152

26. Aziz KT, Best MJ, Naseer Z et al (2018) The association of delirium with perioperative complications in primary elective total hip arthroplasty. Clin Orthop Surg 10:286. https://doi.org/10.4055/ cios.2018.10.3.286

27. Tian J, Chen X, Liu D (2018) Prediction of length of hospital stay and mortality in patients with delirium: a prospective cohort analysis of 200 ICU patients. J Biol Regul Homeost Agents 32:681-685

28. Cereghetti C, Siegemund M, Schaedelin S et al (2017) Independent predictors of the duration and overall burden of postoperative delirium after cardiac surgery in adults: an observational cohort study. J Cardiothorac Vasc Anesth 31:1966-1973. https://doi.org/ 10.1053/j.jvca.2017.03.042

29. Gleason LJ, Schmitt EM, Kosar CM et al (2015) Effect of delirium and other major complications on outcomes after elective surgery in older adults. JAMA Surg 150:1134. https://doi.org/10.1001/ jamasurg.2015.2606

30. Mangusan RF, Hooper V, Denslow SA, Travis L (2015) Outcomes associated with postoperative delirium after cardiac surgery. Am J Crit Care 24:156-163. https://doi.org/10.4037/ajcc2015137

31. Pisani MA, Kong SYJ, Kasl SV et al (2009) Days of delirium are associated with 1-year mortality in an older intensive care unit population. Am J Respir Crit Care Med 180:1092-1097. https:// doi.org/10.1164/rccm.200904-0537OC

32. Almashrafi A, Elmontsri M, Aylin P (2016) Systematic review of factors influencing length of stay in ICU after adult cardiac surgery. BMC Health Serv Res 16:318. https://doi.org/10.1186/ s12913-016-1591-3

33. Bettex D, Rudiger A (2018) Length of ICU stay after cardiac surgery: too long or too short? J Cardiothorac Vasc Anesth 32:26922693. https://doi.org/10.1053/j.jvca.2018.05.045

34. Federführende FachgesellschaftenDeutsche Gesellschaft für Anästhesiologie und Intensivmedizin (DGAI)Deutsche Interdisziplinäre Vereinigung für Intensiv- und Notfallmedizin (DIVI) (2015) S3-Leitlinie: Analgesie, Sedierung und Delirmanagement in der Intensivmedizin (DAS-Leitlinie 2015). Arbeitsgemeinschaft der Wissenschaftlichen Medizinischen Fachgesellschaften (AWMF)

35. Menzenbach J, Guttenthaler V, Kirfel A et al (2020) Estimating patients' risk for postoperative delirium from preoperative routine data - Trial design of the PRe-Operative prediction of postoperative DElirium by appropriate SCreening (PROPDESC) study-a monocentre prospective observational trial. Contemp Clin Trials Commun 17:100501. https://doi.org/10.1016/j.conctc.2019. 100501 
36. (2019) InEK GmbH - Institut für das Entgeltsystem im Krankenhaus, G-DRG-Report Browser 2019

37. Avelino-Silva TJ, Campora F, Curiati JAE, Jacob-Filho W (2018) Prognostic effects of delirium motor subtypes in hospitalized older adults: a prospective cohort study. PLoS ONE 13:e0191092. https://doi.org/10.1371/journal.pone.0191092

38. Steiner LA (2011) Postoperative delirium. Part 1: pathophysiology and risk factors. Eur J Anaesthesiol 28:628-636. https://doi.org/ 10.1097/EJA.0b013e328349b7f5

39. Luetz A, Weiss B, Boettcher S et al (2016) Routine delirium monitoring is independently associated with a reduction of hospital mortality in critically ill surgical patients: a prospective, observational cohort study. J Crit Care 35:168-173. https://doi.org/10. 1016/j.jcrc.2016.05.028

40. Mohanty S, Rosenthal RA, Russell MM et al (2016) Optimal perioperative management of the geriatric patient: a best practices guideline from the American College of surgeons NSQIP and the American Geriatrics Society. J Am Coll Surg 222:930-947. https://doi.org/10.1016/j.jamcollsurg.2015.12.026

41. Watt J, Tricco AC, Talbot-Hamon C et al (2018) Identifying older adults at risk of delirium following elective surgery: a systematic review and meta-analysis. J Gen Intern Med 33:500-509. https:// doi.org/10.1007/s11606-017-4204-x

42. Adogwa O, Elsamadicy AA, Lydon E et al (2017) The prevalence of undiagnosed pre-surgical cognitive impairment and its postsurgical clinical impact in elderly patients undergoing surgery for adult spinal deformity. J Spine Surg 3:358-363. https://doi.org/10. 21037/jss.2017.07.01

43. Panitchote A, Tangvoraphonkchai K, Suebsoh N et al (2015) Under-recognition of delirium in older adults by nurses in the intensive care unit setting. Aging Clin Exp Res 27:735-740. https://doi.org/10.1007/s40520-015-0323-6

44. Neuner B, Hadzidiakos D, Bettelli G (2018) Pre- and postoperative management of risk factors for postoperative delirium: who is in charge and what is its essence? Aging Clin Exp Res 30:245-248. https://doi.org/10.1007/s40520-017-0890-9

45. Bettelli G, Maggi S (2018) Decision-making about surgery in the elderly. Aging Clin Exp Res 30:225-227. https://doi.org/10.1007/ s40520-018-0915-z

46. Ha A, Krasnow RE, Mossanen M et al (2018) A contemporary population-based analysis of the incidence, cost, and outcomes of postoperative delirium following major urologic cancer surgeries. Urol Oncol Semin Orig Investig 36:341.e15-341.e22. https://doi. org/10.1016/j.urolonc.2018.04.012

47. Järvelä K, Porkkala H, Karlsson S et al (2018) Postoperative delirium in cardiac surgery patients. J Cardiothorac Vasc Anesth 32:1597-1602. https://doi.org/10.1053/j.jvca.2017.12.030
48. Salluh JIF, Wang H, Schneider EB et al (2015) Outcome of delirium in critically ill patients: systematic review and meta-analysis. BMJ 350:h2538-h2538. https://doi.org/10.1136/bmj.h2538

49. Pipanmekaporn T, Chittawatanarat K, Chaiwat O et al (2016) The impact of Delirium on clinical outcomes in Multi-Center Thai surgical intensive care units: a prospective cohort study. J Med Assoc Thail Chotmaihet Thangphaet 99(Suppl 6):S226-S232

50. Mufti HN, Hirsch GM (2017) Perioperative prediction of agitated (hyperactive) delirium after cardiac surgery in adults - the development of a practical scorecard. J Crit Care 42:192-199. https:// doi.org/10.1016/j.jcrc.2017.07.045

51. Theologou S, Giakoumidakis K, Charitos C (2018) Perioperative predictors of delirium and incidence factors in adult patients post cardiac surgery. Pragmatic Obs Res 9:11-19. https://doi.org/10. 2147/POR.S157909

52. Strijbos MJ, Steunenberg B, van der Mast RC et al (2013) Design and methods of the Hospital Elder Life Program (HELP), a multicomponent targeted intervention to prevent delirium in hospitalized older patients: efficacy and cost-effectiveness in Dutch health care. BMC Geriatr 13:78. https://doi.org/10.1186/ 1471-2318-13-78

53. Abraha I, Trotta F, Rimland JM et al (2015) Efficacy of non-pharmacological interventions to prevent and treat delirium in older patients: a systematic overview. The SENATOR project ONTOP Series. PLoS ONE 10:e0123090. https://doi.org/10.1371/journal. pone. 0123090

54. Ringaitienè D, Gineitytė D, Vicka V et al (2015) Impact of malnutrition on postoperative delirium development after on pump coronary artery bypass grafting. J Cardiothorac Surg 10:74. https://doi. org/10.1186/s13019-015-0278-x

55. Hempenius L, Slaets JPJ, van Asselt D et al (2013) Outcomes of a geriatric liaison intervention to prevent the development of postoperative delirium in frail elderly cancer patients: report on a multicentre, randomized. Controlled Trial PLoS ONE 8:e64834. https://doi.org/10.1371/journal.pone.0064834

56. Styra R, Larsen E, Dimas MA et al (2019) The effect of preoperative cognitive impairment and type of vascular surgery procedure on postoperative delirium with associated cost implications. J Vasc Surg 69:201-209. https://doi.org/10.1016/j.jvs.2018.05.001

Publisher's Note Springer Nature remains neutral with regard to jurisdictional claims in published maps and institutional affiliations. 